\title{
Iatrogenic Disorders
}

\author{
Lt Gen NR Krishnan, PHs (Retd)*, Brig AS Kasthuri, vsm (Retd) ${ }^{+}$
}

MJAFI 2005; 61 : 2-6

Key Words : Drug interactions; Doctor induced adverse drug reactions; Drug toxicity

$\mathrm{I}^{\mathrm{a}}$ atrogenic disease is the result of diagnostic and therapeutic procedures undertaken on a patient. With the multitude of drugs prescribed to a single patient adverse drug reactions are bound to occur. The Physician should take suitable steps to detect and manage them.

Iatrogenic (of a disease or symptoms) induced in a patient by the treatment or comments of a physician.

Chambers English Dictionary

One of the basic principles in treatment stated by Hippocrates is "First do no harm". Stories of medical remedies causing more harm than good have been recorded from time immemorial. An iatrogenic disorder occurs when the deleterious effects of the therapeutic or diagnostic regimen causes pathology independent of the condition for which the regimen is advised. It would be impossible to provide the benefits of modern medicine if reasonable steps in diagnosis and treatment were withheld because of possible risks [1]. Diagnostic procedures (mechanical and radiological), therapeutic regimen (drugs, surgery, other invasive procedures), hospitalization and treating doctor himself can bring about iatrogenic disorders.

\section{Adverse effects of diagnostic procedures}

\section{Mechanical procedures}

Diagnostic aspiration of fluids may lead to hemorrhage, secondary infection, etc. Rapid pleural or peritoneal fluid aspiration and needle biopsies may lead to shock and even death. Endoscopic procedure may cause perforation of hollow viscus.

\section{Diagnostic radiology}

Reactions to contrast media injected intravenously or intra-arterially may be mild, moderate or severe, and some are potentially fatal. Intravascular contrast media may have a nephrotoxic reaction. Cerebral angiography may cause transient or permanent neurological deficits.
Radioisotopes are safe except in pregnant mothers or in newborn [2].

\section{Adverse effects of therapeutic regimen}

\section{Adverse drug reactions (ADR)}

ADR is defined by World Health Organization as any response for a drug which is noxious, unintended and which occurs at doses normally used for prophylaxis, diagnosis and therapy of disease [3]. ADR can be classified as predictable (side effects, toxicity, super infection, drug interactions) and unpredictable (intolerance, idiosyncrasy, allergy or pseudo allergy) [4].

When fewer than 6 different drugs are given in hospitalized patients, the probability of an adverse reaction is about $5 \%$, but if more than 15 drugs are given, the probability is more than $20 \%$. Of the patients admitted to a General hospital, 2 to $5 \%$ are due to ADR and fatality in patients with ADR varies from $2-12 \%$. ADR occurs in the elderly more frequently [5].

To overcome the inadequacies in the WHO definition, new definition for adverse drug reaction is "an appreciably harmful or unpleasant reaction, resulting from an interaction related to the use of a medicinal product, which predicts hazard from future administration and warrants prevention or specific treatment or alteration of the dosage regimen or withdrawal of the product". They are classified into six types (with mneminics), doserelated (Augmented), non-dose-related (Bizarre), doserelated and time-related (Chronic), time-related (Delayed), withdrawal (End of use), and failure of therapy (Failure) [6].

\section{Anaphylaxis}

Penicillin and other Beta-lactum antibiotics and various types of vaccines and sera, and human insulin, are the most common agents that cause anaphylaxis. Aspirin and other nonsteroidal anti-inflammatory agents (NSAIDs) cause non-IgE mediated anaphylactoid reactions [7].

*Consultant and Dean, GKNM Hospital, Coimbatore, Tamil Nadu, ${ }^{+}$Professor and Head, Department of Medicine, Vydehi Institute of Medical Sciences and Research Center, 82 EPIP Area, Whitefield, Bangalore. 
Drug induced cutaneous manifestations

Some of the cutaneous manifestations are [8]:

1. Alopaecia Cytotoxic agents

2. Erythema multiforme Chlorpropamide, Sulphonamides

3. Exanthematous eruptions

Allopurinol, Anti convulsants

4. Exfoliative dermatitis Gold, streptomycin

5. Fixed drug eruptions

Barbiturates, Tetracyclines

6. Photosensitivity

Griseofulvin, Indomethacin

7. Toxic epidermal necrolysis

Barbiturates, Sulphonamides

Drug induced haematological disorders

\section{Megaloblastic Anaemia (MA)}

Oral contraceptives, phenytoin, phenobarbitone and primidone cause MA due to folic acid deficiency, colchicines, neomycin, paramino salicylic acid (PAS) due to vitamin $\mathrm{B}_{12}$ deficiency and 6-mercaptopurine, 5 flurouracil, hydroxy-urea, acyclovir and zidovudine by interfering with DNA metabolism [9].

\section{Hemolytic anemia}

Drugs causing haemolysis by direct action are phenacetin, PAS, sulphonamides: by immune mechanism are aminopyrine, chlorpromazine, quinine and tetracycline: and in G-6 PD deficient patients, antimalarials (primaquine) and antibiotics (nitrofurantoin) [10].

\section{Aplastic anaemia}

Drugs that regularly produce bone marrow depression: busulphan, cyclophosphamide, chlorambucil, vinblastine, and 6 mercaptopurine. Drugs which rarely produce bone marrow depression: chloramphenicol, penicillamine, sulphonamides, isoniazid, NSAIDSs, analgin, thiouracil, anticonvulsants, anti diabetics, cimetidine, tranquilizers etc [11].

Drugs producing Neutropenia [12]:

Analgesics and NSAIDs :Indomethcin, Phenacetin, Acetaminophen, PhenylButazone and Aminopyrine

Anticonvulsants :Phenytoin, Carbamazepine

Antithyroid drugs :Thiouracil, Methimazole

Phenothiazines :Chlorpromazine

Antiarrhythmic :Quinidine

Drugs that cause thrombocytopaenia [12]:

Alpha-methyldopa, carbimazole, chloramphenicol, cyclosporins, phenylbutazone, quinine, quinidine, rifampicin, sulphonamides etc.

Hazards of blood transfusion[13]:

Complications occur in 2 percent of blood transfusions.

a. Immunological reaction : Allergic-anaphylaxis, fever, haemolysis, non cardiac pulmonary oedema.

b. Non immunological : Circulatory overload, thrombophlebitis and embolism, bacterial contamination, transmission of diseases like malaria, hepatitis, syphilis and AIDS and transfusion siderosis in multiple transfusion.

Drug induced gastro-intestinal diseases [5,7]

\section{Oral lesions}

1. Lichen planus like lesions : methyldopa, chloroquine and propranolol.

2. Lupus erythematosis like lesions : hydralazine, gold. Acid peptic disease : acetyl salicylic acid, NSAIDs, corticosteroids etc.

Pancreatitis : azathioprine, glucocorticoids and oral contraceptives.

Malabsorption : broad-spectrum antibiotics, cholestyramine and neomycin.

\section{Hepatic damage}

Drug induced liver injury is a potential complication of nearly every medication because liver metabolizes virtually all drugs. Acute (acetaminophen, halothane) and chronic (nitrofurantoin, methyldopa) hepatocellular injury, veno occlusive disease (cyclophosphamide) and hepatocellular carcinoma (sex and anabolic hormones) can all occur. There are many new drugs like glyburide, ketoconazole, lisinopril, lovastatin, ticlopidine etc. which were also associated with hepatotoxic reactions. Among causes of fulminant hepatic failure certain drugs like halothane, acetaminophen, phenytoin and alpha methyldopa account for $20-50 \%$ of cases [14].

Respiratory disorders due to drugs $[5,15]$ :

Type of reaction

Example of drug

1.Airway obstruction

(Bronchospasm)

2. Cough

3. Nasal congestion

4.Pulmonary oedema

Beta-Blockers, Adenosine, NSAIDs

ACE inhibitors

Oral contraceptives, Reserpine, Guanithidine

Contrast media, Methadone, Interleukin 2

5.Pulmonary hypertension Fenfluramine

6.Pulmonary infiltration Anticancer agents, Acyclovir, Amiodarone 
7.Pleural disease

8.Pulmonary thromboembolism

\section{Drug induced cardiovascular diseases}

Drug reactions may lead to exacerbation of angina (alpha blockers), arrhythmias (digitals, beta-adrenergic agents, tricyclic anti-depressants and quinine), cardiomyopathy (daunorubicin, emetine and lithium), hypo or hypertension (glucocorticoids and sympathomimetics), pericardial disease (emetine, procainamide and minoxidil), and Torsades de pointes (sparfloxacin) [5].

Renal disorders caused by drugs [16].

The kidney is the main excretory organ of the body and hence affected by most drugs.

1. Directly toxic to the tubular cells: paracetamol, amphotericin B, cisplatin, sulphonamides etc.

2. Function as an antigen or as a hapten and the resulting antigen antibody reaction damages renal interstitium and leads to acute interstitial nephritis : penicillins, cephalosporins, NSAIDs, anticoagulants, gold salts, captopril etc.

3. Renal failure by reducing renal blood flow: noradrenaline and dopamine in high doses. NSAIDs indirectly affect renal blood flow by inhibiting production of prostaglandins.

Analgesic nephropathy - heavy and prolonged consumption of compound analgesic preparations particularly those containing phenacetin can cause chronic renal failure. This analgesic nephropathy is part of a broader analgesic syndrome, which includes hypertension, peptic ulcer, anaemia and recurrent headache.

\section{Syndrome of drug-induced kidney disease}

Common risk factors which precipitate adverse effects include old age, volume-depleted state, preexisting renal dysfunction and co-existing use of other nephrotoxins.

Syndrome Drugs

1. Pre-renal failure/functional NSAIDs, ACErenal failure inhibitors, Diuretics, Interleukin-2, Amphotericin-B.

2. Acute tubular necrosis

Aminoglycosides, Rifampicin, NSAIDs, Cyclosporine, Cisplatin

3. Acute Interstitial nephritis Penicillins, NSAIDs, Allopurinol, Thiazides, Sulfonamides.
4. Thrombotic Mitomycin-C, microangiopathy/hemolytic Cyclosporine, Quinine, uremic syndrome Cocaine, Clopidogrel.

5. Isolated proteinuria with nephritic syndrome

Gold, heroin, Captopril, NSAIDs, IFN-alpha, D-penicillamine.

6. Chronic tubulointerstitial disease

NSAIDs, Thiazides, Lithium, Chinese herb nephropathy, Germanium.

7. Retroperitoneal fibrosis Methysergide, Hydralazine, Methyldopa.

Neurological manifestations [17]

1. Aseptic meningitis

Intravenous immunoglobulin

2. Extra pyramidal lesions

Haloperidol, Methyl dopa, Phenothiazine

3. Peripheral neuropathy Isoniazid, Metronidazole, Gold salts, Nitrofurantoin, Amiodarone, Vaccines.

4. Pseudomotor Cerebri or intracranial hypertension

Amiodarone, Glucocorticoids, Oral contraceptives

5. Convulsions

Amphetamine, Analeptics, Lithium, Phenothiazine

6. Stroke

Oral contraceptives

7. Encephalitis and GuillainBarre syndrome

Anti-rabies vaccination (purified chick embryo cell)

8. Myopathy

Statins

Neuroleptic malignant syndrome - Rigidity, hyperthermia, altered mental status resembling catatonia, labile blood pressure and autonomic dysfunction characterize one of the serious complications of neuroleptic agents like Haloperidol [18].

Drug induced psychiatric syndromes [5]:

\section{Delirium or Confusional state}

2. Depression

3. Drowsiness

4. Hallucination
Anticholinergics, Glucocorticoids, Phenothiazines

Beta blockers, Glucocorticoids, Nifedipine

Antihistamines

Beta blockers, Levodopa, Narcotics 
5. Hypomania, Mania

6. Paranoid states

Glucocorticoids, Sympathomimetics

Drug induced musculoskeletal/rheumatic disorders [19]

Disorder

1. Arthralgia

2. Hyper-uricaemia and Gout

3. Mylagia/Myositis

4. Osteoporosis

5. Scleroderma like disorder

\section{Drug}

Cytotoxic drugs, Ethambutol, Levodopa, Diuretics.

Amphotericin B, Clofibrate, Colchicines, Lovastatin, Levodopa, Rifampicin, Vincristine, Zidovudine.

Anticonvulsants, Methotrexate.

\section{Bleomycin, INH,}

Penicillamine, Silicon
Fluorides, growth hormone, Penicillin, Quinolones (in children), Sulphonamides Cyclosporine, Salicylates Nicotinic acid, Phenytoin, Chloroquine, Cimetidine, Cyclosporines, Gemfibrozil, Penicillamine, Phenytoin, Corticosteroids, Heparin,

Breast implants.

Adverse reactions due to sudden stoppage of drug

Sudden stoppage of drugs can cause[20]:

a a "rebound phenomenon" : relapse with or without exacerbation of the basic disease

b. a "withdrawal phenomenon" : a new clinical syndrome unrelated to the original disease

Antihypertensive drugs: Sudden stoppage of clonidine and alpha methyldopa cause syndrome resembling pheochromocytoma.

Beta-blockers: Sudden stopping of the drug in coronary artery disease may cause infarction, aggravation of angina or rhythm disorders.

Corticosteroids: Withdrawal accidents are seen after prolonged treatment, unrelated to the dose and duration of treatment and relapse of basic disease even in an aggravated form.

Barbiturates: Sudden stoppage in epileptic patients can induce status epilepticus. When used to induce sleep, sudden stoppage can cause acute insomnia, confusion, agitation, hallucinations and convulsions.
Drugs producing malignant diseases[21]:

\section{Leukemia (esp. acute myeloid leukemia)}

2. Cancer of breast and endometrium

3. Cancer of vagina

4. Liver cancer
- Anti cancer agent, Radiotherapy, rarely Chloramphenicol and Phenyl-butazone

- Diethyl stilbesterol

- Anabolic steroids, Oral contraceptives
- Estrogens, Tamoxifen

\section{Drug nutrient interaction}

Drugs may decrease nutrient absorption, increase urinary excretion, directly compete with or antagonize the nutrient from a carrier protein and interfere with the synthesis of an enzyme or coenzyme essential for the metabolism of the nutrient[22].

\section{Drug induced fever}

Drug fever constitutes one percent of all fevers of unknown origin. Any drug can cause fever (antihistamines, barbiturates, iodides, penicillins, phenytoin, propylthiouracil, $\beta$-lactum antibiotics etc). A history of allergy, skin rash or eosinophilia is often absent in cases of drug fever [23].

Adverse reactions following immunization [24]:
1. Inherent vaccine induced

\section{Programmatic errors}

(a) Mild and common - local reaction, fever

(b) Moderately severe and uncommon -suppurative lymphadenitis (BCG vaccination)

(c) Severe and rareEncephalopathy and hypersensitive reactions (paralytic polio following oral polio vaccine).

Septic - toxic shock syndrome and abscess.
Interaction between indigenous and prescription drugs:

Use of indigenous drugs is neither inquired in the drug history nor are the patients advised to avoid such an indiscriminate concurrent use of drugs. Sometimes these factors lead to either a therapeutic failure or a drug interaction or an accentuation of the unknown toxicities of the chemical prescription drugs [25].

Ophthalmological complications [5]
1. Cataract
Busulphan
2. Corneal opacities
Chloroquine 
3. Colour vision alteration Digitalis

4. Glaucoma

5. Optic neuritis

Sympathomimetics

6. Retinopathy

Quinine

Chloroquine

\section{Radiation hazards [5]}

1. Acute and chronic progressive radiation injuries

2. Pneumonitis

3. Glomerulosclerosis and chronic interstitial nephropathy

4. Enteritis and cystitis

5. Venoocclusive disease of liver

6. Bone marrow depression

7. Malignancy

\section{Hazards of hospitalization}

The prevalence of hospital-acquired infections is around $10 \%$. Urinary tract infections and respiratory infections are the commonest. There is increased chance of infections associated with diagnostic and therapeutic procedures and with antibiotic resistant bacterial flora [26].

\section{Physician as the cause of the disease}

The harm that a physician can do is not limited to the imprudent use of medicine or procedure, but may include unjustified remarks and misinterpretation of investigational data. The physician should be aware of the properties of drugs that he prescribes and their potential dangers. Ignorance of the possibility of a reaction is a clear evidence of negligence. The physician should warn the patient of the likely side effects [1,27].

The list of drugs given in this article is in no way complete and only examples are given. Readers should look up the references to have more details. Drugs affecting the fetus or breastfed babies are not discussed.

\section{References}

1. The Editors. The practice of medicine: Iatrogenic disorders. In: Fauci SAS, Braunwald E, Kasper DL and Hauser SL editors. Harrison's Priniciples of Internal Medicine. $15^{\text {th }}$ ed. New York : McGraw Hill 2001;3.

2. Sutton D, Gregson R. Arteriography and interventional angiography. In: Sutton D, editor. Textbook of radiology and imaging. $6^{\text {th }}$ ed New York: Churchill Livingstone 1998;681.

3. WHO. International drug monitoring: the role of national centers, Tech Rep Ser. WHO 1972;498.

4. Kishore K, Nagarkar KM. Adverse drug reaction. Hospital today 1996;35-41.

5. Wood AJJ. Adverse Reactions to Drugs. In: Fauci SAS, Braunwald E, Kasper DL, Hauser SL, editors. Harrison's Principles of Internal Medicine. $15^{\text {th }}$ ed. New York : McGraw Hill 2001;430-8.

6. Edwards IR, Aronson JK. Adverse drug reactions: definitions, diagnosis and management. The Lancet 2002;356:1255-9.

7. Marquarit DL. Anaphylaxis and Drug Reactions. In: Stein JH, editor. Internal Medicine. $5^{\text {th }}$ ed. Boston : Little Brown $1998 ; 1193$.

8. Hood AF. Cutaneous Manifestations of Drug Reactions. In: Stein JH, editor. Internal Medicine. $5^{\text {th }}$ ed. Boston : Little Brown 1998;1312-6,1402.

9. Agarwal MB. Hereditary Hemolytic Anaemia. In: Shah SN editor. API Text Book of Medicine. $7^{\text {th }}$ ed. Mumbai: API 2003;939-44.

10. Nayak J. Megaloblastic Anaemia. In: Shah SN, editor. API Text Book of Medicine. $7^{\text {th }}$ ed. Mumbai: API 2003;934-8.

11. Velu N. Bone Marrow Facture Status. In: Shah SN, editor. API Text book of Medicine. $7^{\text {th }}$ ed. Mumbai: API 2003;963-6.

12. Bichile SK. Neutropenia (granulocytopenia, agranulocytosis). In: Shah SN, editor. API Text Book of Medicine. $7^{\text {th }}$ ed. Mumbai: API 2003;967-8.

13. Kamath SA. Blood Transfusions. In: Shah SN, editor. API Text Book of Medicine. $7^{\text {th }}$ ed. Mumbai: API 2003;980-2.

14. Sherlock S, Dooley J. Drugs and the Liver. In: Sherlock S, editor. Diseases of Live and Biliary System. $11^{\text {th }}$ ed. London: Blackwell Scientific Publications 2002;335.

15. Dowdeswell IRG. Pleural Diseases. In: Stein JH, editor. Internal Medicine. $5^{\text {th }}$ ed. Boston : Little Brown 1998;505-10.

16. Jacob CK. Drugs Toxins and the Kidney. In: Shah SN, editor. API Text Book of Medicine. $7^{\text {th }}$ ed. Mumbai: API 2003;66872.

17. Wadia RS, Dalal PM. Drug induced neuromuscular disorders. J Assoc Physicians India. 1994;42(7):537-9.

18. Aminoff MJ: Parkinson's disease and other Extra Pyramidal Disorders:-Neuroleptic Malignant Syndrome. In: Fauci SAS, Braunwald E, Kasper DL Hauser SL, editors. Harrison's Principles of Internal Medicine. $15^{\text {th }}$ ed. New York: McGraw Hill 2001;2405.

19. Joshi VR, Balakrishnan C. Drug induced Rheumatic Disorders. J Assoc Physicians India. 1994;42(1):805-8.

20. Wahi S, Wahi PL. Adverse reactions on stoppage of drugs. J Assoc Physicians India. 1986;34:205-8.

21. Advani SH. Basic consideration of oncology. In: Shah SN, editor. API Text Book of Medicine. $7^{\text {th }}$ ed. Mumbai : API 2003;98790.

22. Weser E Young EA. Nutrition in Internal Medicine: Durg Nutrient Interaction. In: Stein JH, editor. Internal Medicine. $5^{\text {th }}$ ed. Boston : Little Brown 1998;2099-112.

23. Tauber MG. Fever of unknown Origin-Drug fever. In: Stein $\mathrm{JH}$, editor. Internal Medicine. $5^{\text {th }}$ ed. Boston : Little Brown 1998:1378.

24. Adverse Events Following Immunization, CSSM Review 1994;231-5.

25. Rai J. A potential for interactions between indigenous and prescription drugs. In: Shah SN, editor. API Text Book of Medicine. $7^{\text {th }}$ ed. Mumbai : API 2003;52:164-6.

26. Mandal BK, Dunbar EM, Mayon White RJ. Hospital Acquired infection. In: Mandal, editor. Infectious Disease. $5^{\text {th }}$ ed, Bangalore: Blackwell Science 1996;26.

27. Sarangi MP, Maini A, Sharma GK. Drug and Product Liability. Ind J Clinical Practice. 1995;5(9):94-6. 